\title{
Polyphenol Composition and Antioxidant Activity of Two Autochthonous Brassicaceae of the Campania Region, Southern Italy
}

\author{
Florinda Fratianni ${ }^{1}$, Federica Cardinale ${ }^{1}$, Autilia Cozzolino ${ }^{1}$, Tiziana Granese $^{1}$, Selenia Pepe ${ }^{1}$, \\ Riccardo Riccardi $^{2}$, Patrizia Spigno ${ }^{2}$, Raffaele Coppola ${ }^{1}$, Filomena Nazzaro $^{{ }^{*}}$ \\ ${ }^{1}$ Institute of Food Science, ISA-CNR, Avellino, Italy; ${ }^{2}$ Cooperative ARCA, Acerra, Italy. \\ Email: ${ }^{*}$ mena@isa.cnr.it
}

Received November 20 $0^{\text {th }}$, 2013; revised December 20 ${ }^{\text {th }}, 2013$; accepted December $27^{\text {th }}, 2013$

Copyright (C) 2014 Florinda Fratianni et al. This is an open access article distributed under the Creative Commons Attribution License, which permits unrestricted use, distribution, and reproduction in any medium, provided the original work is properly cited. In accordance of the Creative Commons Attribution License all Copyrights (C) 2014 are reserved for SCIRP and the owner of the intellectual property Florinda Fratianni et al. All Copyright (C) 2014 are guarded by law and by SCIRP as a guardian.

\section{ABSTRACT}

Torzella (Brassica oleracea acephala) is one of the most ancient kinds of cauliflower developed in the Mediterranean area. Broccolo (Brassica oleracea botrytis cimosa), var. "San Pasquale" is a leafy vegetable cultivated in Campania too, mainly in the province of Naples. We evaluated the polyphenols content and the antioxidant activity of these two Brassicaceae, provided by the same experimental plant of the Campania region. Both vegetables showed high content of total polyphenols (6.37 mM GAE/g and $2.24 \mathrm{mM} \mathrm{GAE} / \mathrm{g}$ of Torzella and Broccolo, respectively), and a remarkable antioxidant activity $\left(\mathrm{EC}_{50} 1.53 \mathrm{mg}\right.$ and $\mathrm{EC}_{50} 6.51 \mathrm{mg}$, in Torzella and Broccolo, respectively). Polyphenol composition, determined by ultra performance liquid chromatography (UPLC), allowed us to detect a certain number of compounds (gallic, ferulic, chlorogenic, p-coumaric and caffeic acids, catechin, luteolin, naringenin) common to both species. Therefore, epicatechin was found only in the extract of san Pasquale broccoli; on the contrary, rutin and apigenin were detected only in the extracts of torzella broccoli. Hence, such products can be considered therapeutic functional foods due to their extraordinary reserve of secondary metabolites and bioactive constituents that are beneficial for managing and preventing several chronic illnesses in humans.

\section{KEYWORDS}

Brassicaceae; Antioxidants; Polyphenols

\section{Introduction}

Bioactive compounds, such as polyphenols and antioxidants, present in plant-based foods provide several health benefits beyond basic nutrition and are positively involved in the prevention of chronic diseases. Many studies found several interesting biological properties of plant foods, such as anti-inflammatory, antioxidant, antimutagenic, antiviral, antimicrobial and antiquorum sensing activities [1-4]. Cruciferous vegetables act as a precious source of natural antioxidants, which contribute in protecting the human body against damages due to the oxidative processes and represent a rich source of anti-

*Corresponding author. microbial compounds [5,6]. The family Brassicaceae (or Cruciferae) consists of about 350 genera and 3500 species. Genus Brassica, the most important one present within family Brassicaceae, includes some crops and species of relevant worldwide economic and health importance, such as Brassica oleracea L., Brassica napus L. and Brassica rapa L. The same species can be used for several purposes according to different forms or types, including food and forage forms. The beneficial properties of Brassica vegetables can be ascribable to their complex mixture of biomolecules with antioxidant activity, mainly to the presence of phenolic compounds $[7,8]$ (Podsedek, 2007; Janhangir, et al., 2009), a large number of compounds (more than 8000 ) generally produced by 
all vegetables as secondary metabolites and way of defence against biotic and abiotic stresses. In the Campania region (Southern Italy) different Brassica broccoli are present as typical products, such as San Pasquale broccoli (Brassica oleracea botrytis var. cimosa, Figure 1(a)) and Torzella broccoli (Brassica oleracea var acephala, Figure 1(b)). San Pasquale broccoli is cultivated mainly in the plan area of the province of Naples and in that nocerino-sarnese (Naples and Salerno). Its leaves are liry, dark greeny and pulpy. Torzella, also called torza riccia or Greek cauliflower, is one of the most ancient Brassica developed in the eastern countries of the Mediterranean area. It has pulpy and curly dark green leaves and is much resistant to low temperatures. In the past centuries, torzella was cultivated mainly in the Acerra-Nola area (province of Naples) of the Campania region; however, after the second half of the XIX ${ }^{\text {th }}$ century, it risked to miss completely. Casually found in an isolated area of the province of Naples, its genetic material was recovered, analyzed, and propagated in different areas of the region, enriching again the regional biodiversity with an ancient product of important health benefits.

\section{Materials and Methods}

\subsection{Extraction of Polyphenols}

Samples of Broccoli san Pasquale and Torzella were collected from the experimental farm "Marsocci" in Acerra, Naples, Italy. Edible portions were homogenized with 3 volumes of ethanol and kept at $4^{\circ} \mathrm{C}$ overnight, to avoid the extraction of glucosinolates, usually extracted at hot temperatures. The procedure was performed on a horizontal shaker. After centrifugation $(11,600 \times \mathrm{g}$, Biofuge, Beckmann, CA, USA), the supernatant was collected, dried and re-suspended in $3 \mathrm{ml}$ of sterile deionized water.

\subsection{Colorimetric Analysis of Total Phenolics}

Total phenolics were measured following using the Folin-Ciocalteu reagent [8]. The absorbance was evaluated at room temperature at $\lambda=760 \mathrm{~nm}$ using a Cary 50 Uv/Vis spectrophotometer (Varian-Agilent Italia, Cernusco sul Naviglio, Italy). Quantification was based on a standard curve generated with gallic acid. The results were expressed as the mmol of gallic acid equivalent (GAE)/g of sample.

\subsection{Free Radical Scavenging Capacity}

The free radical scavenging capability of the extract was determined using the stable radical 2,2-diphenyl-1-picrylhydrazyl (DPPH) assay [9]. The analysis was performed in microplates by adding $7.5 \mu \mathrm{L}$ of extract to 303 $\mu \mathrm{L}$ of a methanolic DPPH solution (153 mM). Next, the

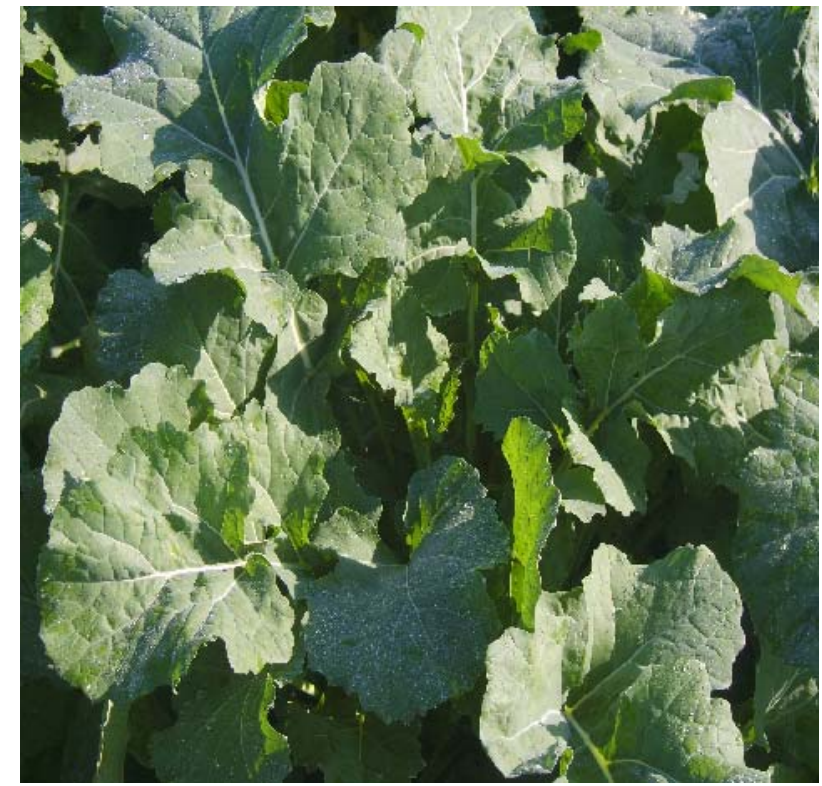

(a)

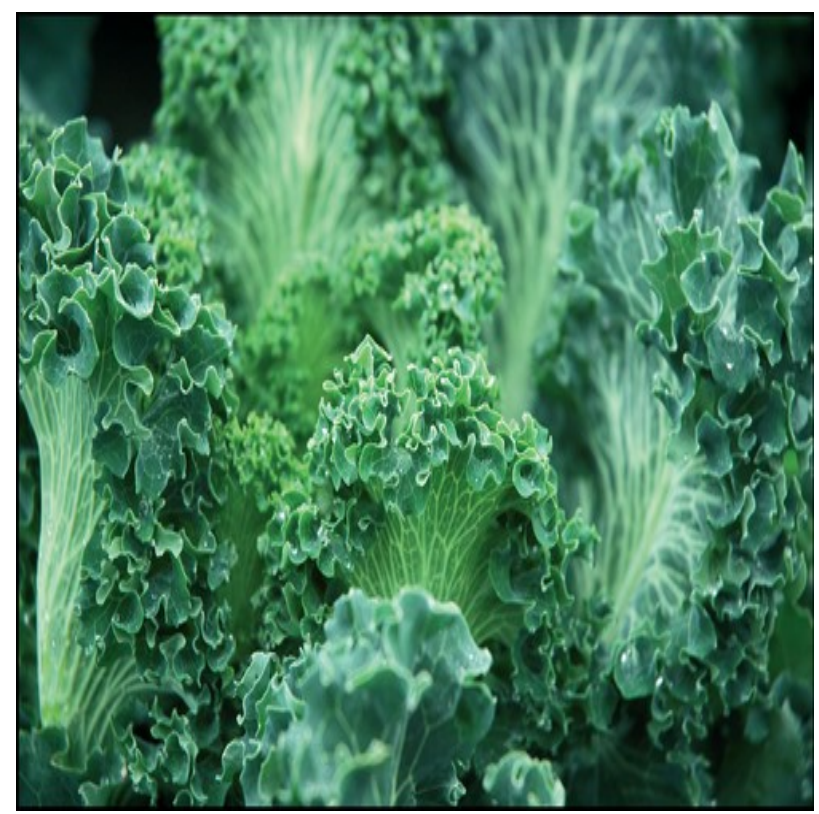

(b)

Figure 1. (a) San Pasquale broccoli (Brassica oleracea botrytis cimosa; (b) Torzella or Torza riccia (Brassica oleracea acephala).

absorbance at $\lambda=517 \mathrm{~nm}$ was measured (Cary 50 MPR, Varian, USA). The absorbance of DPPH without antioxidant (control sample) was used as for baseline measurements. The scavenging activity was expressed as the $50 \%$ effective concentration $\left(\mathrm{EC}_{50}\right)$, which was defined as the sample concentration $(\mathrm{mg})$ necessary to inhibit the DPPH radical activity by $50 \%$ during a 60 -min incubition. These experiments were performed in triplicate, and the results are expressed as the mean values \pm standard 
deviation.

\subsection{Chromatographic Analysis}

The analysis of polyphenols was carried out by using an ACQUITY ${ }^{\mathrm{TM}}$ Ultra Performance liquid chromatography (UPLC) system (Waters, Milford, MA, USA) linked to a PDA 2996 photodiode array detector (Waters). Empower software was used to control the instruments and for data acquisition and processing. The extracts and the standards (previously dissolved in methanol) were filtered $(0.45 \mu \mathrm{m}$, Waters, Milford, MA, USA) before analysis. The analyses were performed at $30^{\circ} \mathrm{C}$ using a reversed phase column (BEH C ${ }_{18}, 1.7 \mu \mathrm{m}, 2.1 \times 100 \mathrm{~mm}$, Waters) [10]. The mobile phase consisted of solvent $\mathrm{A}$ ( $7.5 \mathrm{mM}$ acetic acid) and solvent B (acetonitrile) at a flow rate of $250 \mu \mathrm{L} \cdot \mathrm{min}^{-1}$. Gradient elution was employed, starting with 5\% B for 0.8 $\mathrm{min}$, then $5 \%-20 \%$ B over $5.2 \mathrm{~min}$, isocratic $20 \%$ B for $0.5 \mathrm{~min}, 20 \%-30 \%$ B for $1 \mathrm{~min}$, isocratic $30 \% \mathrm{~B}$ for 0.2 min, $30 \%-50 \%$ B over $2.3 \mathrm{~min}, 50 \%-100 \%$ B over 1 $\mathrm{min}$, isocratic $100 \% \mathrm{~B}$ for $1 \mathrm{~min}$, and finally $100 \%-5 \% \mathrm{~B}$ over $0.5 \mathrm{~min}$. At the end of this sequence, the column was equilibrated under the initial conditions for $2.5 \mathrm{~min}$. The pressure ranged from 6000 to 8000 psi during the chromatographic run. The effluent was introduced into an LC detector (scanning range: $210-400 \mathrm{~nm}$, resolution: 1.2 $\mathrm{nm})$. The injection volume was $5 \mu \mathrm{L}$.

\section{Results and Discussion}

Spectrophotometric analyses were carried out to evaluate the polyphenolic concentration and the antioxidant activity of the two extracts obtained by San Pasquale broccoli (Brassica oleracea botrytis var. cimosa, and Torzella broccoli (Brassica oleracea var acephala. Results are shown in Table 1.

On the whole, the two varieties of broccoli cultivated in the Campania region exhibited a good content both of total polyphenols and antioxidant activity. Therefore, torzella showed a greater amount of total polyphenols compared to San Pasquale broccoli (6.37 mM GAE/ml of extract versus $2.24 \mathrm{mM} \mathrm{GAE} / \mathrm{ml}$ of extract, respectively). Such results are in accordance with those reported for other Brassica species [11], where the presence of a similar amount of total polyphenols was ascertained. The antioxidant capacity of the Brassica species is generally related to its phenolic profile and content, especially flavonoids, since phenolic compounds demonstrated a higher antioxidant activity than vitamins and carotenoids $[12,13]$. The presence of a different amount of total polyphenols probably affected the antioxidant activity which, on the other hand, although good in both cases, resulted of relevant importance, from a health point of view, in the case of torzella: in this case, in fact, less than
$2 \mathrm{mg}$ of its extract were sufficient to neutralize at $50 \%$ the activity of $1 \mathrm{ml}$ of the stable radical DPPH. A major antioxidant activity could be due not only to a different total polyphenols content but also to a different content of singular polyphenols [5]; in our case, chromatographic analysis, performed through UPLC and shown in Figure 2 (San Pasquale broccoli) and Figure 3 (torzella broccoli), respectively, gave similar profiles but different amount of the singular compounds taken into consideration. The type and the amount of each known polyphenols, identified on the basis of the standards available, are shown in Table 2. We identified different biomolecules, basically gallic, chlorogenic, p-coumaric, ferulic acids, as well as catechin, rutin, luteolin, naringenin, apigenin and epicatechin, Such results are in accordance with previous works which identified in Brassica different hydroxycinammic acids, such as caffeic, p-coumaric and ferulic acid, as well as benzoic acid derivatives, such as gallic acid [14]. In B. oleracea var. costata grown in vitro, a high number of chlorogenic acids, flavonoids and hydroxycinnamic derivatives were detected $[15,16]$, indicating that the in vitro production of shoots can become important as a dietary source of compounds with a health protective potential. Taking into account the standard available for our research, the two UPLC

Table 1. Total Polyphenols (TP), and antioxidant activity of san Pasquale and torzella broccoli.

\begin{tabular}{ccc}
\hline & $\begin{array}{c}\text { Polyphenol } \\
\text { content } \\
(\mathrm{mM} \mathrm{GAE} / \mathrm{ml})\end{array}$ & $\begin{array}{c}\text { Antioxidant } \\
\text { activity } \\
\left(\mathrm{mg} \mathrm{EC}_{50}\right)\end{array}$ \\
\hline San Pasquale broccoli & $2.24 \pm 0.12$ & $6.51 \pm 1.21$ \\
Torzella broccoli & $6.37 \pm 1.15$ & $1.53 \pm 0.09$ \\
\hline
\end{tabular}

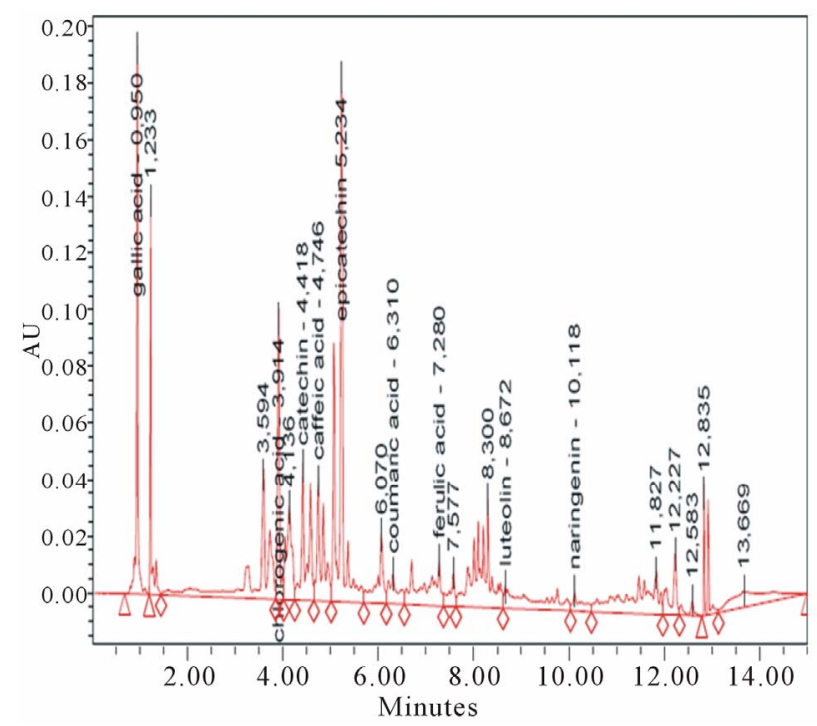

Figure 2. Polyphenol profile of San Pasquale broccoli obtained by UPLC analysis. 


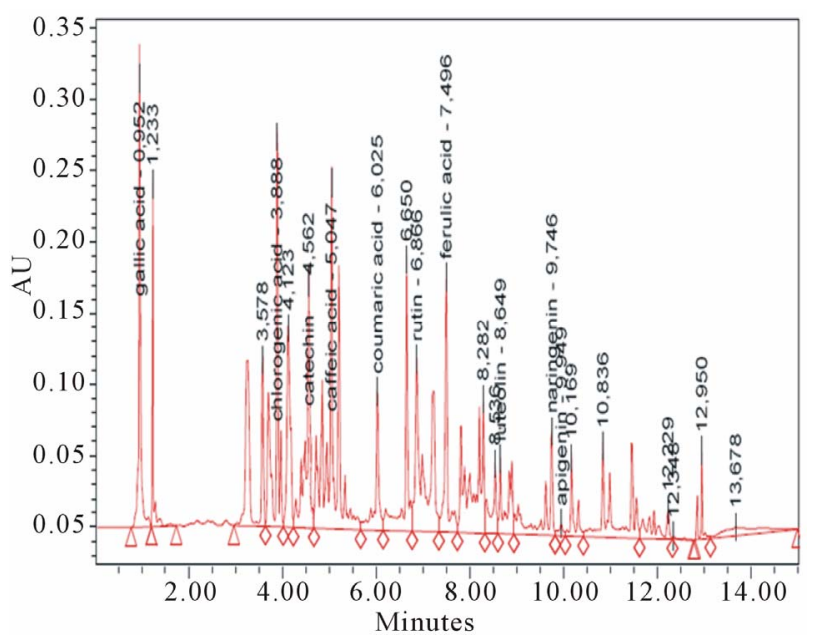

Figure 3. Polyphenol profile of Torzella broccoli obtained by UPLC analysis.

Table 2. Quantitative analysis of polyphenols present in Broccolo San Pasquale and Torzella, obtained after UPLC analysis.

\begin{tabular}{ccc}
\hline & San Pasquale broccoli & Torzella \\
\hline Gallic acid & $38.65 \pm 1.26$ & $76.06 \pm 11.14$ \\
Chlorogenic acid & $101.15 \pm 5.36$ & $178.71 \pm 12.32$ \\
Catechin & $140.03 \pm 7.64$ & $205.5 \pm 25.64$ \\
Caffeic acid & $35.26 \pm 2.57$ & $250.25 \pm 23.15$ \\
Coumaric acid & $5.8 \pm 0.63$ & $23.03 \pm 1.41$ \\
Rutin & - & $48.00 \pm 4.24$ \\
Ferulic acid & $12.08 \pm 2.13$ & $47.52 \pm 5.04$ \\
Luteolin & $7.38 \pm 1.32$ & $14.88 \pm 2.64$ \\
Naringenin & $2.08 \pm 0.09$ & $24.62 \pm 2.56$ \\
Apigenin & - & $2.63 \pm 0.09$ \\
Epicatechin & $65.6 \pm 2.35$ & - \\
\hline
\end{tabular}

The data represent the mean of three independent experiments and are expressed as micrograms/gr of product \pm standard deviation.

polyphenol profiles of San Pasquale and torzella broccoli were similar, but the amount of the singular metabolites present in each of them was different. Chlorogenic acid and catechin resulted particularly abundant, but more concentrated in torzella than in San Pasquale broccoli. Therefore, all polyphenols resulted more abundant in the extract obtained from torzella than from San Pasquale, with a difference in terms of concentration ranging from two times (luteolin and gallic acid) to 22 times (naringenin). The most remarkable difference, indeed, was exhibited by caffeic acid which, although plentiful in the San Pasquale variety, with a concentration of $35.2 \mu \mathrm{g} / \mathrm{gr}$ of product, was in absolute the most abundant metabolite present in the extract of torzella $(250.25 \mu \mathrm{g} / \mathrm{gr}$ of prod- uct). Three metabolites might be utilized as metabolic markers of typicity between the two species of Brassica cultivated in the Campania region: rutin and apigenin were detected only in the extracts of torzella; on the other hand epicatechin was found only in the San Pasquale broccoli extracts. These metabolites were also found in different tissues of crops from the family Brassicaceae [17], including Sinapis alba, Thlaspi arvense, Camelina sativa, Crambe spp. and several other genera of the family Brassicaceae

\section{Conclusion}

The traditional vegetal panorama of Campania region, in southern Italy, is characterized by a rich genetic biodiversity and represents, at the same time, an inestimable richness of the regional agro-food sector. The correct identification and protection of such vegetables, as well as the study of their biochemical and nutritional aspects is an essential instrument also to preserve the local economy and the areas of the region not yet urbanized. Such aspects become still more important taking into account that nowadays the preference of great food markets is addresses towards products standardized; such polity caused, in the last years, a drastic reduction in number of traditional species and varieties (often with high functional properties) with a concurrent and dramatic decrease of genetic variability. Vegetables belonging to the family Brassicaceae are rich food sources of natural antioxidants and possess a high potential to manage against oxidative stress and, thus, act as strong anticancer as well as anti-degenerative foods. Therefore, the well-known potential of these phytochemical compounds for the maintenance of health and protection against heart disease and cancer [18], is also raising interest among scientists and food manufacturers as consumers move towards functional foods with specific health effects. An interesting aspect will be to clarify the interactions between the genotype of the different Brassica and the external environment and their effect on the polyphenol composition in plants to identify those varieties with the best healthy properties. At the moment, the results obtained by the biochemical characterization of these two Brassica cultivated in the Campania region, comfort us to proceed for a deeper characterization, also in terms of glucosynolates and biological activity, with the aim to safeguard and valorize their production at regional and national level.

\section{Acknowledgements}

This research was funded by Project SALVE ("Safeguard of the vegetal genetic resources of the Campania region"), PSR 2007-2013, meas. 214, action f2, of the Campania 
Regional Council, Italy.

\section{REFERENCES}

[1] C. J. Dillard and J. B. German, "Phytochemicals: Nutraceuticals and Human Health," Journal of the Science of Food and Agriculture, Vol. 80, No. 12, 2000, pp. 17441756.

http://dx.doi.org/10.1002/1097-0010(20000915)80:12<17 44::AID-JSFA725>3.0.CO;2-W

[2] F. Nazzaro, F. Fratianni and R. Coppola, "Quorum Sensing and Phytochemicals," International Journal of Molecular Sciences, Vol. 14, No. 6, 2013, pp. 12607-12619. http://dx.doi.org/10.3390/ijms140612607

[3] F. Fratianni, L. De Martino, A. Melone, V. De Feo, R. Coppola and F. Nazzaro, "Preservation of Chicken Breast Meat Treated with Thyme and Balm Essential Oils," Journal of Food Science, Vol. 75, No. 8, 2010, pp. M528M535. http://dx.doi.org/10.1111/j.1750-3841.2010.01791.x

[4] F. Fratianni, A. Di Luccia, R. Coppola and F. Nazzaro, "Mutagenic and Antimutagenic Properties of Aqueous and Ethanolic Extracts from Fresh and Irradiated Tuber aestivum Black Truffle: A Preliminary Study," Food Chemistry, Vol. 102, No. 2, 2007, pp. 471-474. http://dx.doi.org/10.1016/j.foodchem.2006.04.014

[5] M. E. Cartea, M. Francisco, P. Soengas and P. Velasco, "Phenolic Compounds in Brassica Vegetables," Molecules, Vol. 16, 2011, pp. 251-280. http://dx.doi.org/10.3390/molecules16010251

[6] F. Nazzaro, F. Fratianni, R. Riccardi, P. Spigno and R. Coppola, "Antimicrobial and Anti Quorum Sensing Activities of Two Typical Brassica Cultivars Present in the Campania Region (Southern Italy)," Proceedings of the International Conference on Antimicrobial Research (ICAR 2010), Valladolid, 3-5 November 2010, p. 104.

[7] A. Podsedek, D. Sosnowska, M. Redzynia and B. Anders, "Antioxidant Capacity and Content of Brassica oleracea Dietary Antioxidants," International Journal of Food Science and Technology, Vol. 41, Suppl. 1, 2006, pp. 4958. http://dx.doi.org/10.1111/j.1365-2621.2006.01260.x

[8] V. L. Singleton and J. A. Rossi, "Colorimetry of Total Phenolic with Phosphomolybdic-Phosphotungstic Acid Reagents," American Journal of Enology and Viticulture, Vol. 16, No. 3, 1965, pp. 144-158.

[9] W. Brand-Williams, M. E. Cuvelier and C. Berset, "Use of a Free Radical Method to Evaluate Antioxidant Activity," LWT_Food Science and Technology, Vol. 22, No. 1, 1995, pp. 25-30.

[10] F. Fratianni, R. Coppola and F. Nazzaro, "Phenolic Com- position and Antimicrobial and Antiquorum Sensing Activity of an Ethanolic Extract of Peels from the Apple Cultivar Annurca," Journal of Medicinal Food, Vol. 14, No. 9, 2011, pp. 957-963. http://dx.doi.org/10.1089/jmf.2010.0170

[11] T. Bahorun, A. Luximon-Ramma, A. Crozier and O. I. Aruoma, "Total Phenol, Flavonoid, Proanthocyanidin and Vitamin C Levels and Antioxidant Activities of Mauritian Vegetables," Journal of the Science of Food and Agriculture, Vol. 84, No. 12, 2004, pp. 1553-1561. http://dx.doi.org/10.1002/jsfa. 1820

[12] G. W. Plumb, K. R. Price, M. J. C. Rhodes and G. Williamson, "Antioxidant Properties of the Major Polyphenolic Compounds in Broccoli," Free Radical Research, Vol. 27, No. 4, 1997, pp. 429-435. http://dx.doi.org/10.3109/10715769709065782

[13] R. Llorach, J. C. Espin, F. A. Tomas-Barberan and F. Ferreres, "Valorization of Cauliflower (Brassica oleracea L. var. botrytis) by-Products as a Source of Antioxidant Phenolics," Journal of Agricultural and Food Chemistry, Vol. 51, No. 8, 2003, pp. 2181-2187. http://dx.doi.org/10.1021/jf021056a

[14] Z. X. Fang, Y. X. Hu, D. H. Liu, J. C. Chen and X. Q. Ye, "Changes of Phenolic Acids and Antioxidant Activities during Potherb Mustard (Brassica juncea, Coss.) Pickling," Food Chemistry, Vol. 108, No. 3, 2008, pp. 811817. http://dx.doi.org/10.1016/j.foodchem.2007.11.033

[15] F. Ferreres, C. Sousa, D. M. Pereira, P. Valentao, M. Taveira, A. Martins, J. A. Pereira, R. M. Seabra and P. B. Andrade, "Screening of Antioxidant Phenolic Compounds Produced by in Vitro Shoots of Brassica oleracea L. var. costata DC," Combinatorial Chemistry \& High Throughput Screening, Vol. 12, No. 3, 2009, pp. 230-240. http://dx.doi.org/10.2174/138620709787581756

[16] M. Taveira, D. M. Pereira, C. Sousa, F. Ferreres, P. B. Andrade, A. Martins, J. A. Pereira and P. Valentao, "In Vitro Cultures of Brassica oleracea L. var. costata DC: Potential Plant Bioreactor for Antioxidant Phenolic Compounds," Journal of Agricultural and Food Chemistry, Vol. 57, No. 4, 2009, pp. 1247-1252. http://dx.doi.org/10.1021/jf803496x

[17] J. Onyilagha, A. Bala, R. Hallett, M. Gruber, J. Soroka and N. Westcott, "Leaf Flavonoids of the Cruciferous Species, Camelina sativa, Crambe spp. Thlaspi arvense and Several Other Genera of the Family Brassicaceae," Biochemical Systematics and Ecology, Vol. 31, No. 11, 2003, pp. 1309-1322. http://dx.doi.org/10.1021/jf803496x

[18] A. Scalbert and G. Williamson, "Dietary Intake and Bioavailability of Polyphenols," Journal of Nutrition, Vol. 130 , No. 8, 2000, pp. 2073S-2085S. 